\title{
Legal and Health Response to COVID-I9 in the Arab Countries
}

This article was published in the following Dove Press journal:

Risk Management and Healthcare Policy

\author{
Hasan Falah Hasan \\ Faculty of Law, An-Najah National \\ University, Nablus, Palestine
}

Correspondence: Hasan Falah Hasan Faculty of Law, An-Najah National University, Nablus, Palestine

Tel +97059702272I

Email hfalah003@gmail.com
Background: Arab countries account for almost $6 \%$ of the global population, yet they make up only $5 \%$ of the total cases and less than $3 \%$ of the global death toll attributed to COVID19. COVID-19 has put the health systems in the various Arab Countries and their ability to deliver healthcare services under tremendous strain. The capacity and stability of any health system is important in any type of response to the pandemic, in order to ensure an effective and efficient delivery of care to the public through COVID-19 and beyond. The objective of this study is to identify the various response of health systems in Arab Countries to COVID19, and highlight the legal and health challenges faced during the pandemic. The study identified both gaps and good practices that may be utilized in order to guide the efforts in response to COVID-19 and the recovery efforts once the pandemic is over.

Methods: To determine why the response of some health systems in Arab Countries responses are more effective than others, a three-step framework is adopted which includes, detection, containment, and treatment stages. In order to identify which countries are excelling at detection, containment, and treatment stages, several indicators were selected for each stage. To be able to understand the legal and health challenges of response to the COVID-19 pandemic, an analysis of the health systems, the resources in terms of quality and access, health workforce, and finance was conducted. Secondary data published by the Global Burden of Disease Study, and the Global Change Data Lab of the University of Oxford was used to study identified gaps and good practices to guide the responses to COVID-19 and recovery efforts once the pandemic is over.

Results: The epidemiologic record demonstrates that that certain Arab countries are managing to control the pandemic, through a combination of mitigation strategies, suppression strategy and elimination strategy. There are several barriers and challenges in Arab health systems which have been amplified due to COVID-19 and if ignored may pose a further significant challenge in the future. Health systems in Arab countries are not sufficiently equipped to handle all healthcare needs related to COVID-19, in particular issues relating to administration, equity, finances, the supply side of healthcare, and usage of information technology.

Conclusion: In Arab counties, the standard response to COVID-19 was enforced by new health laws, which consist of a combination of the traditional disease control measures (testing, contact-tracing, social distancing), population-based physical distancing (including stay-at-home orders, school and business closures, and social gathering bans), travel limits (including travel bans, and border closures), and economic support measures. Acceptable healthcare quality and access, sufficient health workforce, and sufficient funds are the most imperative needs in the health system in Arab counties to provide a sustainable response to the COVID-19 pandemic.

Keywords: COVID-19, Arab countries, health systems, health workforce, health finance, taxes, legal issues, health quality 


\section{Introduction}

The World Health Organization (WHO) declared the novel coronavirus disease (COVID-19) a global pandemic on March 11, 2020. ${ }^{1}$ Since the influenza pandemic in 1918, the COVID-19 pandemic has become the most overwhelming universal challenge in recent history. By September 24, 2020, more than 30 million confirmed cases and one million deaths related to COVID-19 have been reported globally. ${ }^{2}$ About $80 \%$ of cases are mild or asymptomatic, $15 \%$ are severe cases and $5 \%$ are critical cases which require the use of ventilators. The elderly and those with preexisting chronic health diseases account for about $90 \%$ of deaths. ${ }^{3}$ There are twenty-two Arab countries: Algeria, Bahrain, Comoros, Djibouti, Egypt, Iraq, Jordan, Kuwait, Lebanon, Libya, Mauritania, Morocco, Oman, Palestine, Qatar, Saudi Arabia, Somalia, Sudan, Syria, Tunisia, United Arab Emirates and Yemen account for almost 6\% of the global population, yet they make up only $5 \%$ of the total cases and less than $3 \%$ of the global death toll attributed to COVID- $19{ }^{2}$

Genetic variations of viruses, such as the one that causes COVID-19, are common and expected. Patients with and without symptoms are known to be contagious. Documented infections in healthcare workers indicate human-to-human transmission. ${ }^{4}$ The main transmission routes for person-to-person spread are contact transmission and respiratory droplet. The transmission rate is reported to be high for this novel strain of coronavirus when compared to its predecessors. ${ }^{5}$

COVID-19 has put health systems under strain in terms of being able to deliver of healthcare services. The capacity of a health system is of considerable importance to a country's response to the pandemic. For example, mortality rates may rise as hospitals become overwhelmed and have fewer resources to tackle the pandemic. The devastating effects of the pandemic have also induced an extraordinary number entry of patients to ICUs departments, raising the ethical and legal concerns. In addition to the health crisis, economies of the Arab Countries reeled when confronted with the staggering loss of life and restrictions placed on education, business, travel, and trade. This led to a rise of legal issues such as access to medicines and intellectual property, disease surveillance and technology, isolation and quarantine measures, movement and social distance restrictions, state of public health emergency in addition to the availability and access of vaccines.
To overcome these challenges in Arab countries, health laws, policies, and strategies are currently being formulated. Arab countries implemented pandemic response plans which significantly limited the spread of COVID$19 .^{6}$ To allow admission of a larger number of critically ill patients, new resources were developed to increase the number of ICU beds. The transmission and mortality rates in Arab countries initially were kept lower than the global average, ${ }^{7}$ however, the rates increased later. The appropriate adoption of health laws and social rules such as social distancing or the wearing of face-mask protection minimizes the risk of infection transmission in general population and in high-risk patients who are more subject to hospital admission for COVID-19. Therefore, the need for stringent laws and strategies to manage the pandemic in order to meet these challenges in Arab countries is quite visible.

In order to successfully control the pandemic, it is important to determine why some health system in Arab Countries responses are more effective than others, and to understand the health and legal challenges of responding to COVID-19. The objective of this study is to identify the responses of health systems in Arab Countries, and highlight the legal and health challenges faced during the pandemic. The study identified gaps and good practices to guide the responses to COVID-19 and recovery efforts once the pandemic is over.

\section{Methods}

There are twenty-two Arab countries; Algeria, Bahrain, Comoros, Djibouti, Egypt, Iraq, Jordan, Kuwait, Lebanon, Libya, Mauritania, Morocco, Oman, Palestine, Qatar, Saudi Arabia, Somalia, Sudan, Syria, Tunisia, United Arab Emirates and Yemen. The geographical area of the Arab countries is spreads across 13 million $\mathrm{km} 2$. There are over 430 million inhabitants in these, where $30 \%$ of the population is aged less than 18 years, and about $7 \%$ are aged over 65 years. ${ }^{8}$ The GDP of these countries combined is at a total of 2.8 trillion US\$ (nominal), equivalent to 7.5 trillion US\$ (Power Purchasing Parity), ranks 11th globally. ${ }^{9}$ Most of the Arab countries rank moderately on Human Development (HDI) and Healthcare Access and Quality (HAQ) Indices. ${ }^{10}$

The World Health Organization defines a health system as

All the human, financial and material resources and organizations that produce health interventions and actions 
whose primary purpose is to improve or maintain health through individual and public health services and through inter-sectoral participation. ${ }^{11}$

To achieve the desired health outcomes, the health system framework identifies six building blocks: service delivery, health workforce, information, medical products, vaccines and technologies, financing, and leadership. ${ }^{9}$ The WHO's strategic framework for emergency preparedness (2017) emphasizes health systems' resilience as a core prerequisite for an effective response to epidemics and pandemics. It also involves emergency risk management and preparedness towards creating a health system with its key components being more resilient. ${ }^{12}$

By having access to effective vaccines and enforcement of health laws, can health system prevent COVID-19 infections. However, in order to help determine why some health systems in Arab Countries responses are more effective than others, three-step quality indicators have been adopted in this research. To identify which countries are excelling at detection, containment, and at the treatment stages, several indicators were selected for each stage which includes:

1. Detection: Three detection indicators were used in this research: number of tests per capita, tests in relation to confirmed deaths, and number of tests per confirmed case. ${ }^{2}$

2. Containment: Four containment indicators were used in this research: deaths per capita, deaths doubling time, cases per capita, and cases doubling time. $^{2}$

3. Treatment: Given the limited evidence available on the efficacy of case management measures, only one treatment indicator was used: case fatality rate. ${ }^{2}$

The dataset used for the detection, containment, and treatment domains was made accessible by the Global Change Data Lab of the University of Oxford. ${ }^{2}$ The dataset obtained was in the form of an Excel file, containing data, which included about the number of cases, number of deaths, number of tests, population, prevalence of diabetes, and cardiovascular death rates. The observations were listed by country and by date.

To understand the legal and health challenges of response to COVID-19, an analysis of the various health systems resources in Arab Countries in terms of quality and access, health workforce, and finance was conducted.
Secondary dataset published by the Global Burden of Disease Study ${ }^{13}$ was used. The data set included important indicators on quality, access, and health workforce for 195 countries. In addition to the 22 Arab countries, a number of organizations such as Organization for Economic Cooperation and Development (OECD) countries for comparison purpose were included in the data set. It is acknowledged in the study that there is a limitation with crosscountry comparisons and the reason is that spatial dynamics of the COVID-19 pandemic are different in each country and are evolving at different rates. However, the 22 Arab countries and the OECD countries were carefully selected because they all recorded their first COVID-19 cases between late January and late February 2020. There are also notable similarities among the Arab countries in terms of history, language, societal development, religion, culture, and lifestyles. Data were then cleaned, coded, and analyzed.

\section{Results}

To review the efforts of Arab countries in the COVID-19 detection phase, three indicators were used: number of tests per capita, number of tests per confirmed case, and number of tests per confirmed death. ${ }^{2}$ It is important to monitor the above indicators because with COVID-19 pandemic it is not quite clear the number of total cases, and the number of confirmed cases are only known. Figure 1 presents the number of COVID-19 tests performed per 1000 people in the selected Arab and OECD countries, by September 24th, 2020.

Figure 1 demonstrates that Japan, for example, is behind the majority of countries in the number of completed tests, while the UAE and Bahrain are the highest in the number of tests being conducted. The United Arab Emirates and Bahrain implemented blanket testing strategies that do not differentiate between high and non-high risk groups and test everyone. However, Japan implemented a testing strategy that focuses specifically on high-risk groups such as healthcare workers or high-risk locations such as those individuals living in nursing homes, the elderly, etc. Figure 2 presents the average number of tests performed per confirmed case. Countries such as New Zealand, Australia and the UAE have the highest ratio of tests to confirmed case, which provide more of a precise picture of the actual situation and the number of COVID-19 cases are expected to have a more precise estimate of total number of COVID-19 cases, as compared to countries with the lowest ratio being in countries such as Qatar and the USA. 


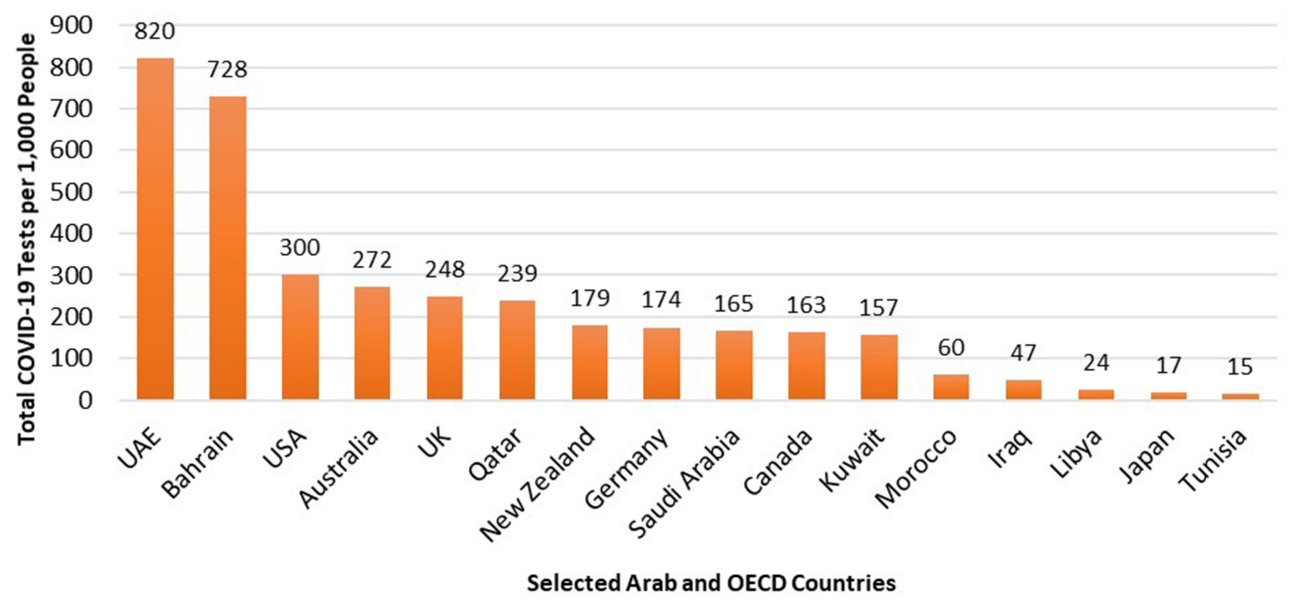

Figure I Total COVID-19 tests per 1000 people, Sep 24, 2020 (Source: Global Change Data Lab).

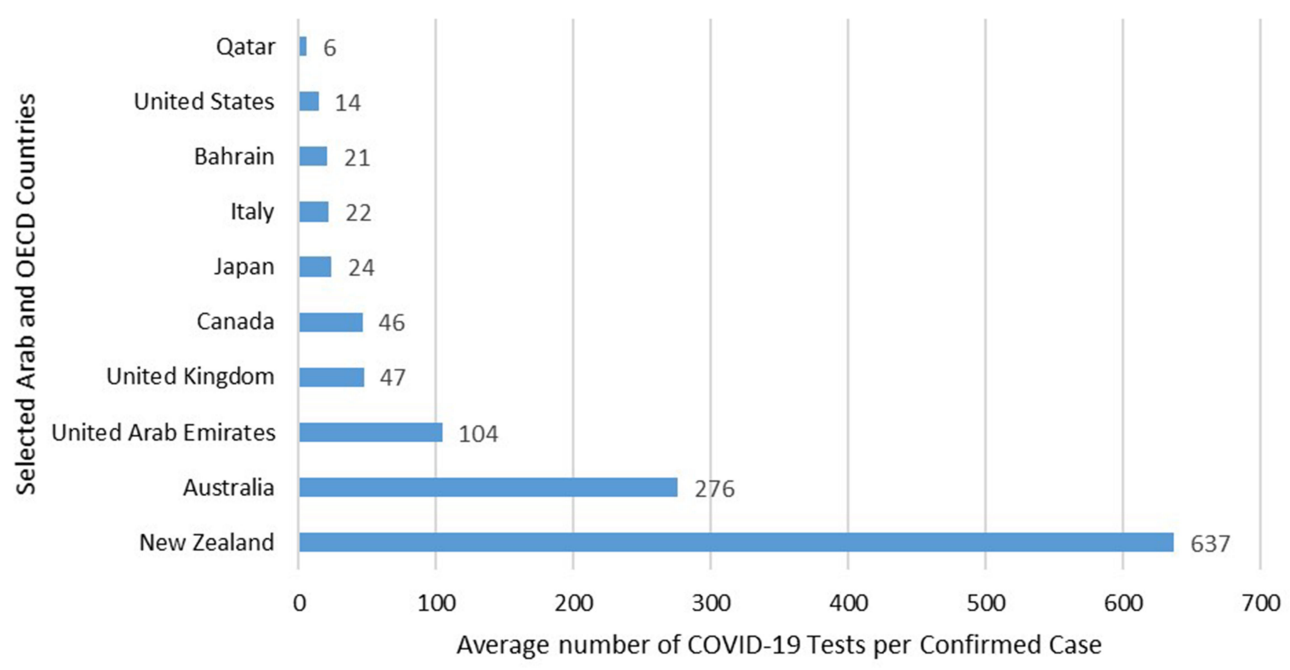

Figure 2 Average number of COVID-19 tests per confirmed case, Sep 24, 2020 (Source: Global Change Data Lab).

Figure 3 presents the total number of COVID-19 tests and the total number of confirmed deaths per million people. A high number is preferable. The more testing which is done, the more precise and clearer picture of the situation to COVID-19. Three groups of countries emerge Group 1: UAE and Bahrain; Group 2: Japan, Tunisia, Morocco, New Zealand, Australia, Qatar, Kuwait, Saudi Arabia, Canada, Switzerland and Iraq. Group 3: USA and the UK.

\section{Containment}

To review the efforts of countries at the containment stage, four indicators were selected: deaths per capita, deaths doubling time, cases per capita, and cases doubling time. ${ }^{2}$ Figure 4 presents the total number of COVID-19 cases per million and the doubling time of cases. It was noted that if the doubling time is longer, the rate of transmission tends to be lower.

Figure 5 presents the number of confirmed COVID-19 deaths per million and the death doubling time. Overall, 1 , Arab countries show fewer deaths per million and a lower doubling time for confirmed deaths compared to most OCED countries.

\section{Treatment}

Many countries reported developing antiviral drugs to manage the spread of COVID-19, however, there is no single treatment which has clinically been approved. In order to review the efforts of countries at the treatment stage and given the limited evidence available on the efficacy of case management measures, one treatment indicator being the case fatality rate CFR which has been 


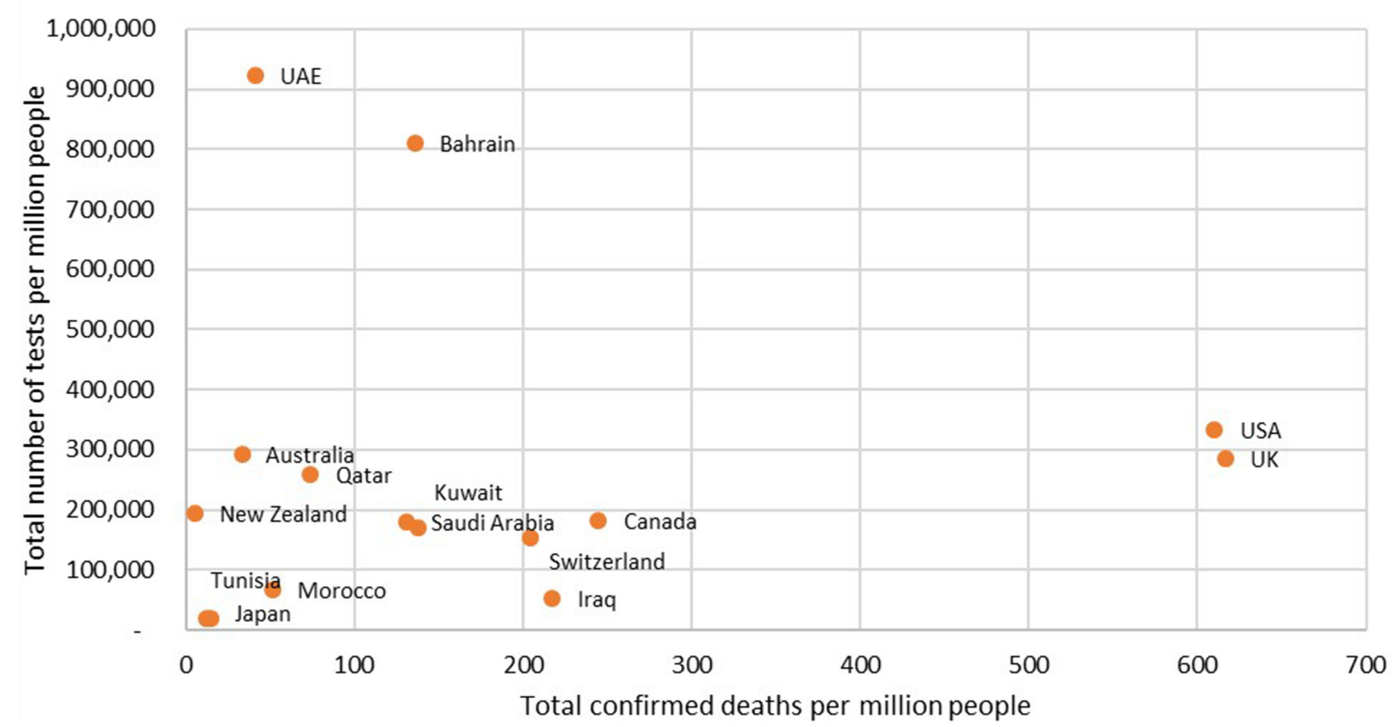

Figure 3 COVID-19 tests vs confirmed deaths per capita, Sep 24, 2020 (Source: Global Change Data Lab).

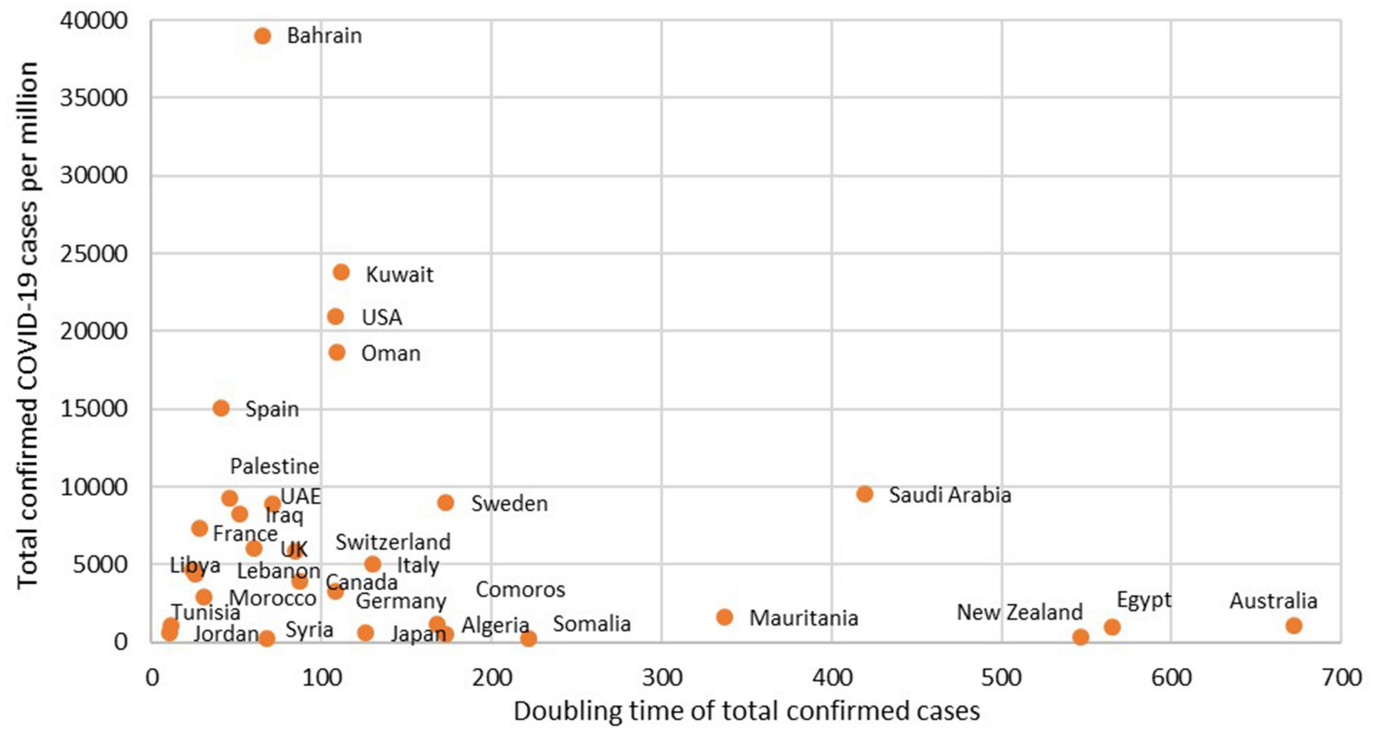

Figure 4 Total confirmed COVID-19 cases per million vs doubling time of total confirmed cases, Sep 24, 2020 (Source: Global Change Data Lab).

adopted in this study Figure 6 presents CFR, which is the ratio of deaths to confirmed COVID-19 cases.

The mortality risk of COVID-19 is affected by the age of the population. Higher CFRs are seen in older population which means that 32 million people over the age of 60 years in the Arab Countries more susceptible to COVID-19 complications. ${ }^{14}$ About $95 \%$ of COVID-19 deaths occur in those over the age of 60 years; with more than $50 \%$ of deaths occur in people aged over 80 years. Figure 7 demonstrates that people over the age of 70,80, 90 years are $3,4.5$, and 5 times, respectively, more likely to die than those aged 60 years. ${ }^{15}$
The mortality risk of COVID-19 is affected by various underlying health conditions. Higher CFRs are in those with Non-Communicable Diseases (NCDs) such as cardiovascular disease or diabetes. The mortality risk of COVID-19 is affected also by underlying risk factors such as smoking, obesity, and physical inactivity, which puts 90 million tobacco users, 185 million overweight or obese individuals, and about 130 million physically inactive individuals at higher risk of becoming severely ill with COVID-19 due to these risk factors and NCDs. ${ }^{16}$ More than $10 \%$, and $7 \%$ of people diagnosed with COVID-19 and had a cardiovascular 


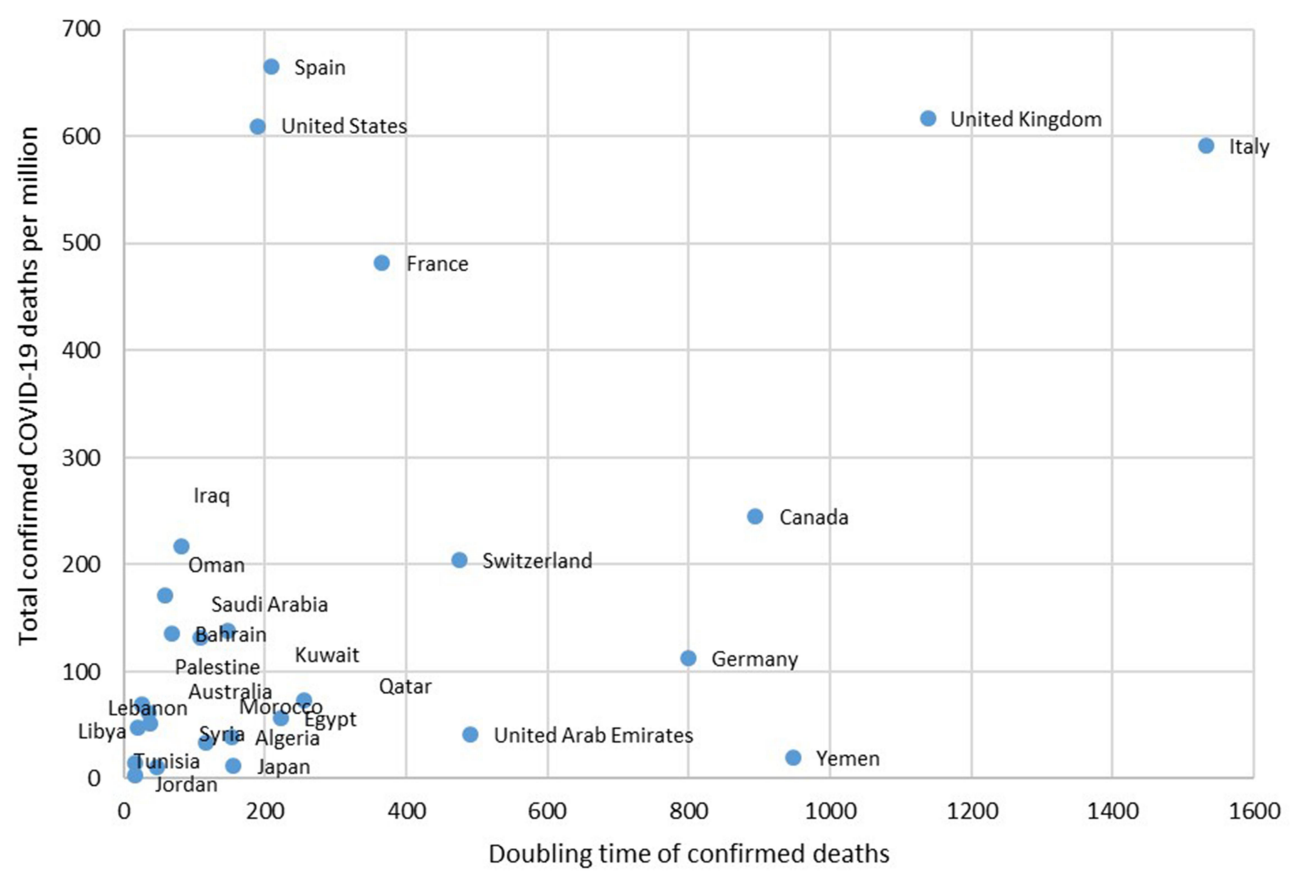

Figure 5 Total confirmed COVID-19 deaths per million vs doubling time of confirmed deaths, Sep 24, 2020 (Source: Global Change Data Lab).

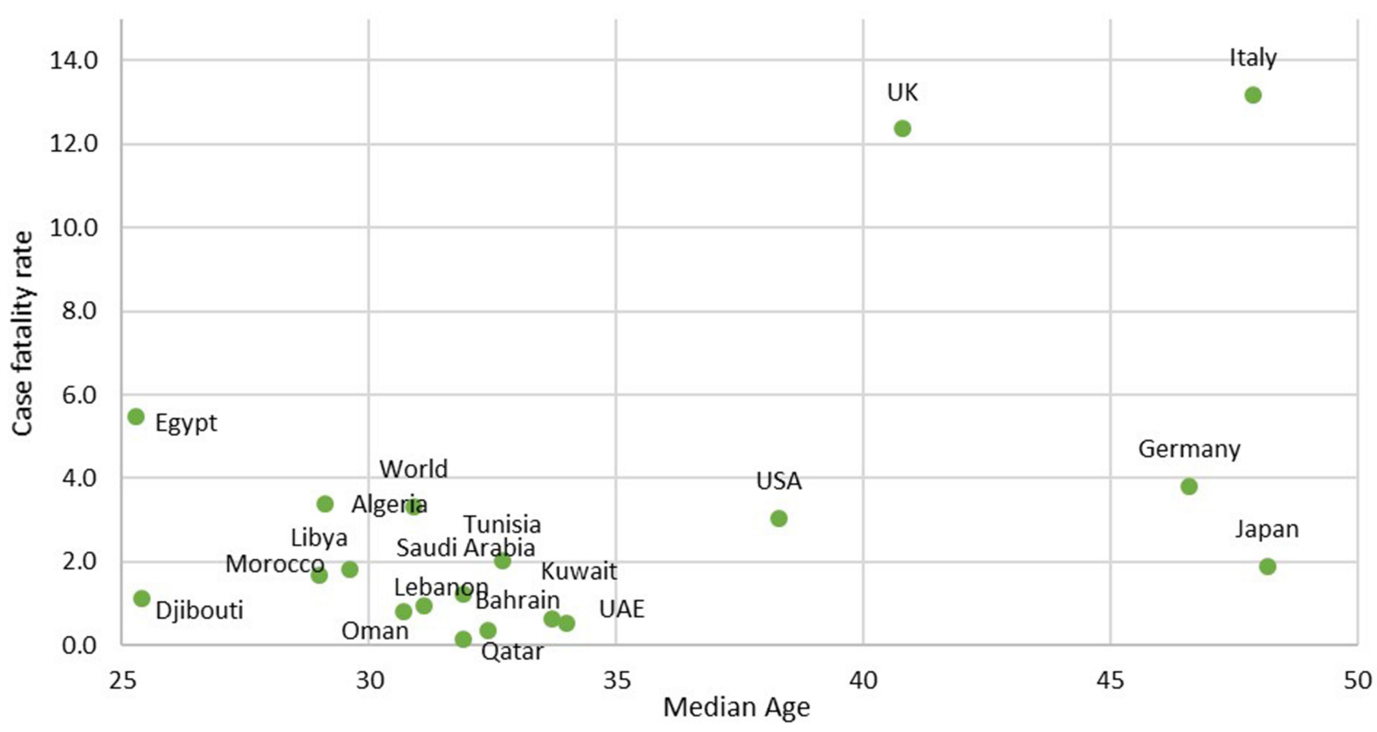

Figure 6 Case fatality rate of COVID-19 vs median age, Sep 24, 2020 (Source: Global Change Data Lab).

disease or diabetes died, respectively. ${ }^{17}$ Figure 8 , presents the prevalence of diabetes, cardiovascular death rate and COVID-19 case fatality rate in Arab countries, the size represents the case fatality rate.

Environmental pollution is an important factor in increasing the COVID-19 global increase in deaths. ${ }^{18}$ Both negative and positive implications on the social and surrounding environment have been reported. ${ }^{19}$ One of the positive implications is the reduction in
Environmental pollution is reduced up to $30 \%$, and commuting has been reduced up to $90 \%$ as a result of COVID-19 movement restriction measures. ${ }^{20}$ This reduction will reduce the morbidity and mortality related due to air pollution. ${ }^{21}$

A key strategy to prevent widespread COVID-19 infection and reduce its morbidity and mortality is to develop a vaccine to protect against the infection. Figure 9 summarizes the number of vaccinations per million in selected countries. 


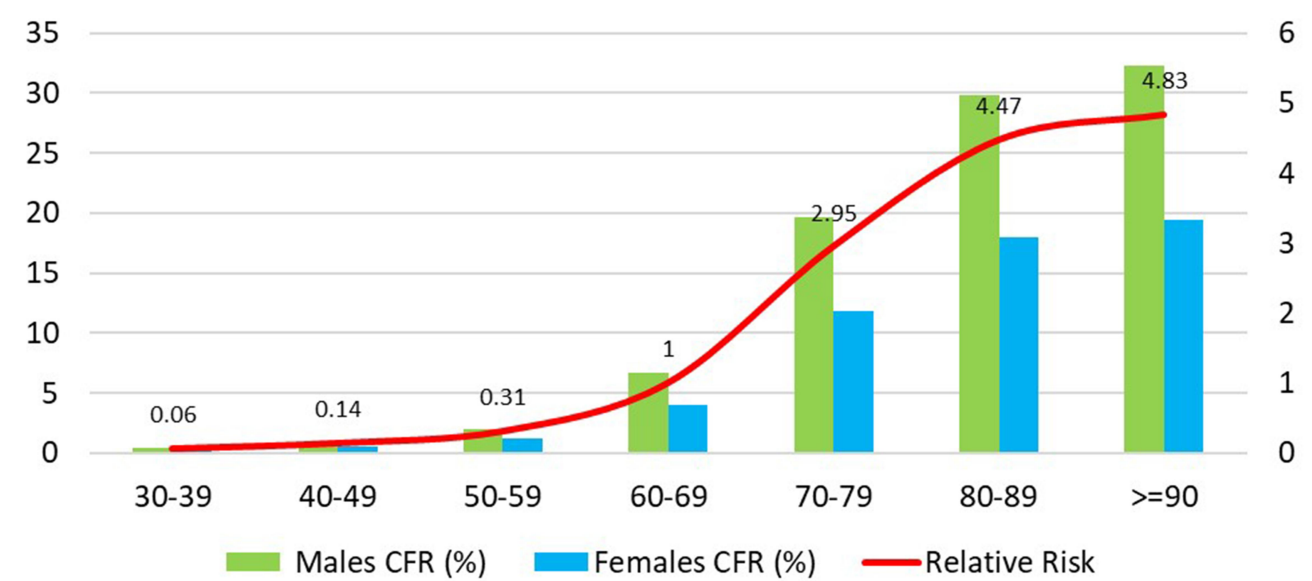

Figure 7 Case-fatality rate and relative risk estimates by age and sex (Source: The Epidemiological Characteristics, 2020 and Onder G, 2020).

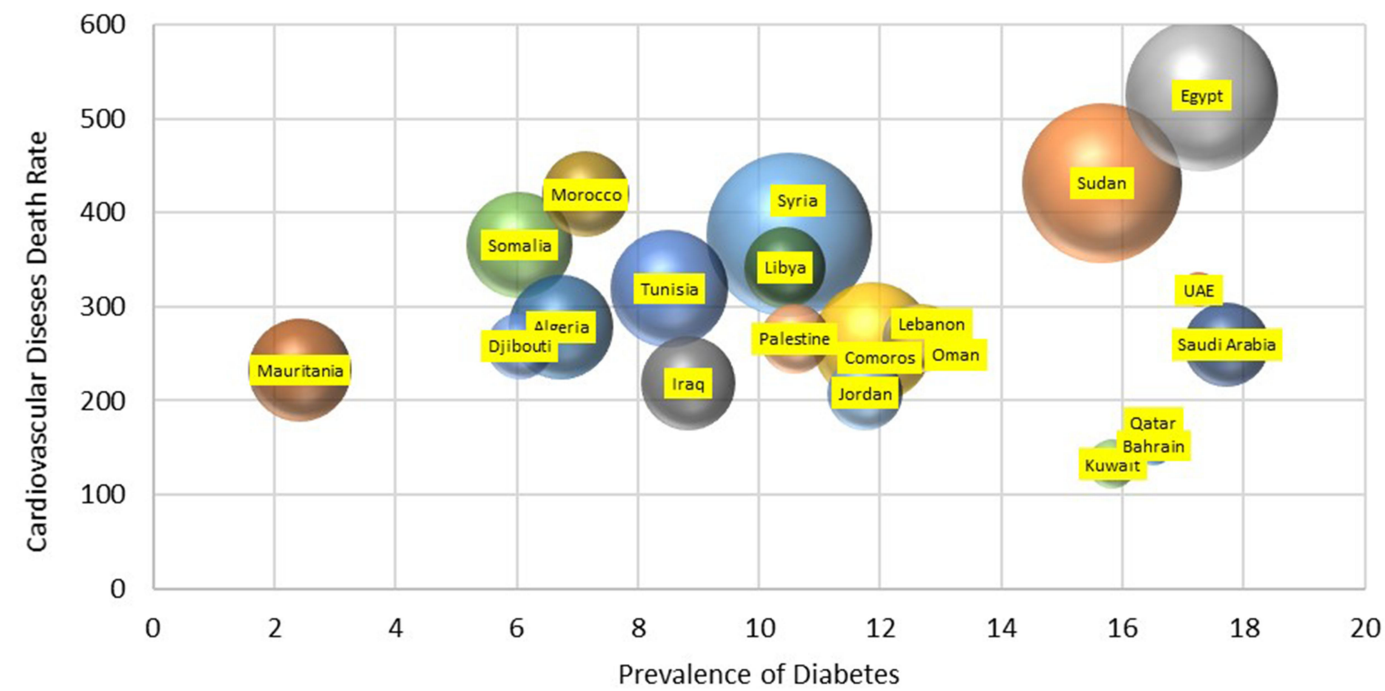

Figure 8 Prevalence of diabetes, cardiovascular death rate and COVID-19 case fatality rate in Arab countries. (Source: The Epidemiological Characteristics, 2020 and Onder G, 2020).

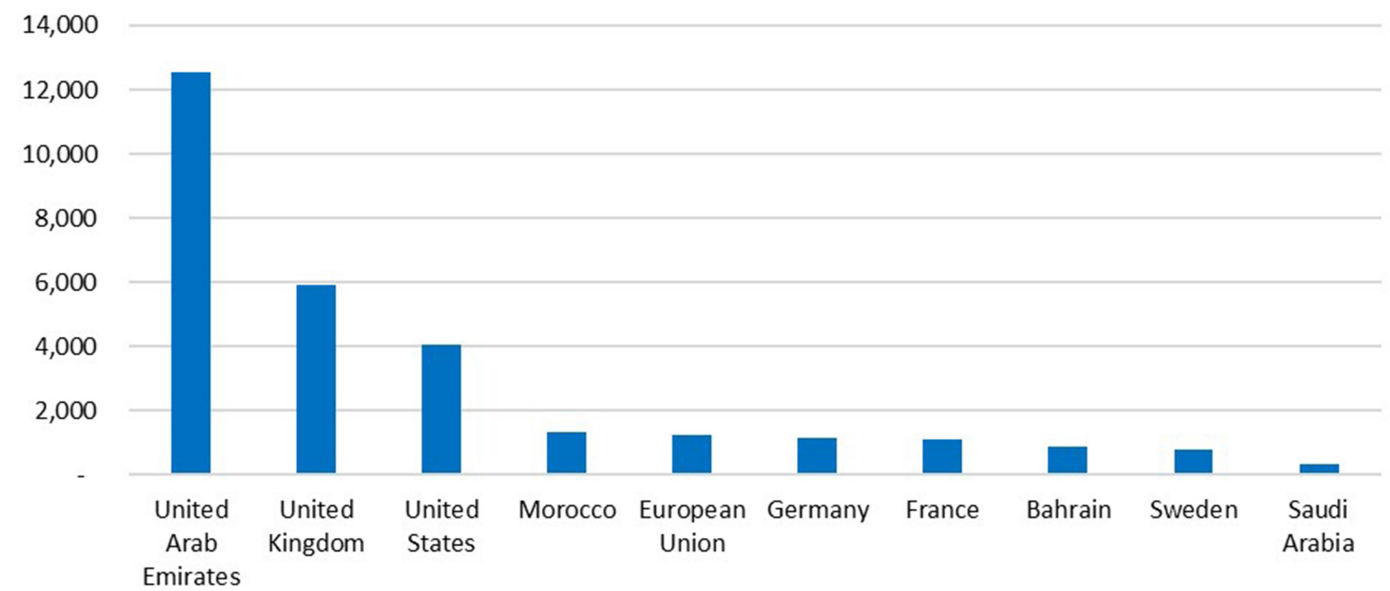

Figure 9 The number of vaccinations per million in selected countries. 


\section{Health System Resources Access and Quality}

None of the Arab Countries achieved more than 90 or less than 10 on the Health and Quality (HAQ) Index. ${ }^{8}$ The moderate Health and Quality (HAQ) Index performance of Arab countries may in fact contribute to the low number of deaths from COVID-19, as shown in Figure 10.

\section{Health Workforce}

Two measures of health service readiness are the availability and density of health workforce. WHO estimates a shortfall of 18 million workers by 2030 , mostly in lowincome countries. ${ }^{22}$ Similar challenges are experienced in Arab countries, and this need becomes much greater due to COVID-19. ${ }^{23}$ When a comparison is made, the total confirmed deaths due to COVID-19 per million people, with the density of physicians and nurses per 10,000 population, there is no clear correlation in Arabic countries (Figure 11). This highlights the complexity of the issue and the prevalence of a number of factors that contribute to death.

\section{Financial Support and Taxes}

Globally, per capita health expenditure reached approximately $\$ 1128$ compared to $515 \$$ in Arab Countries in 2019. Globally, government health spending as percent of total health spending reached $75 \%$ compared to $51 \%$ in Arab countries in 2016. Out-of-pocket health spending reached 19\% compared to 38\% in Arab countries in 2016. Most out-of-pocket spending was used to cover medicines.
Figure 12 compares total confirmed deaths due to COVID19 per million vs health spending per capita.

COVID-19 recovery can be used to increase tax revenues without imposing higher taxes, through information sharing and a wide society response approach. ${ }^{5}$ Economic and Social Commission for Western Asia (ESCWA), initial estimates of the impact of the Coronavirus pandemic show that the Arab region may lose around $\$ 42$ billion in income, decline exports by $\$ 28$ billion, and $\$ 420$ billion in market capital in $2020 .^{24}$ To counter this, several Arab countries provided $\$ 226$ billion stimulus packages to support citizens and businesses, of which $62 \%$ spent in the UAE and Saudi Arabia. About 43\% of the money spent to support COVID-19 activities were in fact spent on financial support policies, $32 \%$ on multiple policy categories, and $16 \%$ on general policy support. The percentage of spending was $31 \%$ on multiple policy measure, $31 \%$ on liquidity support and $6 \%$ on healthcare systems. ${ }^{21}$

\section{Discussion}

In order to track the responses of health systems in Arab countries to COVID-19, a three-step framework: detection, containment, and treatment was used.

\section{Detection}

As part of the first stage, to assess the detection phase, three indicator numbers are used as part of tests per capita, tests in relation to confirmed deaths, and number of tests per confirmed case. The results of the study demonstrate that the containment of COVID-19 is

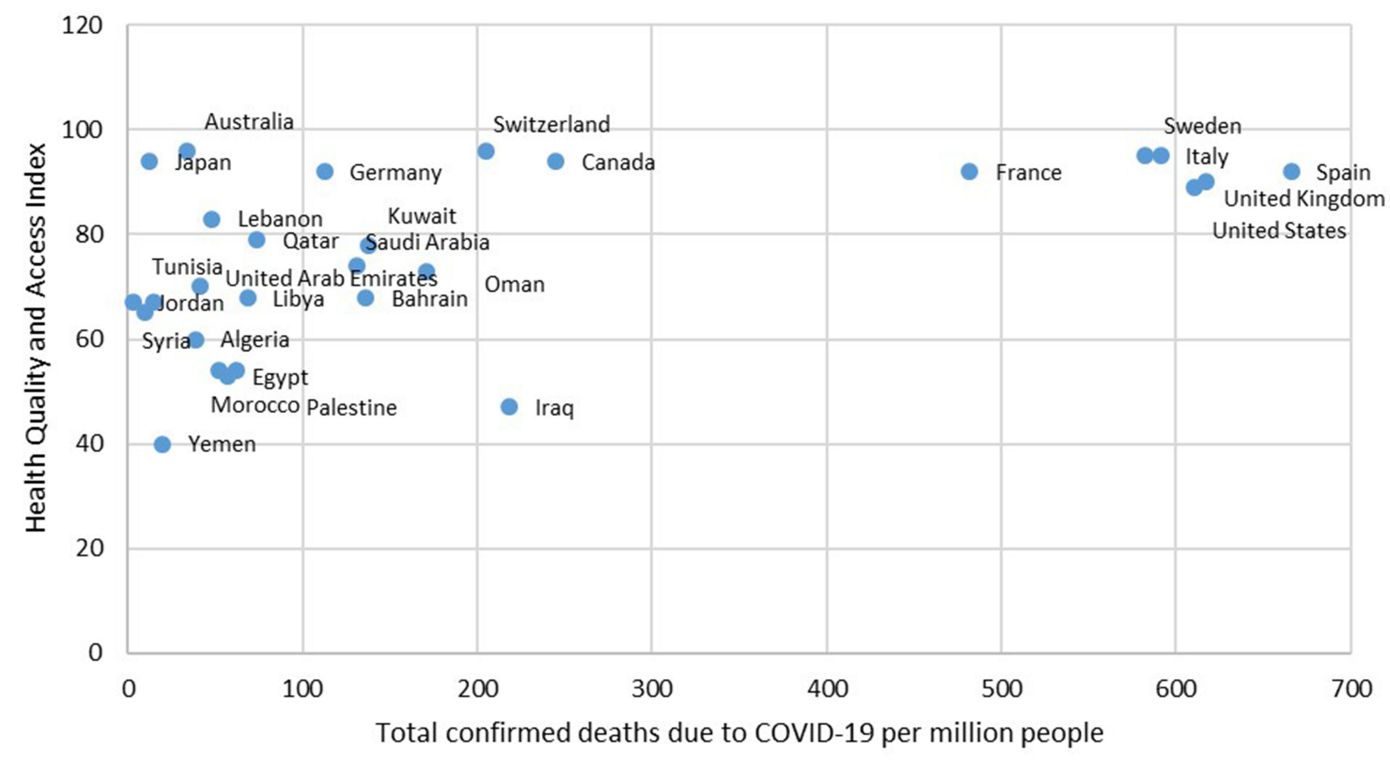

Figure 10 Health Quality and Access Index in Arab countries, 2018 (Source: Global Burden of Disease Study). 


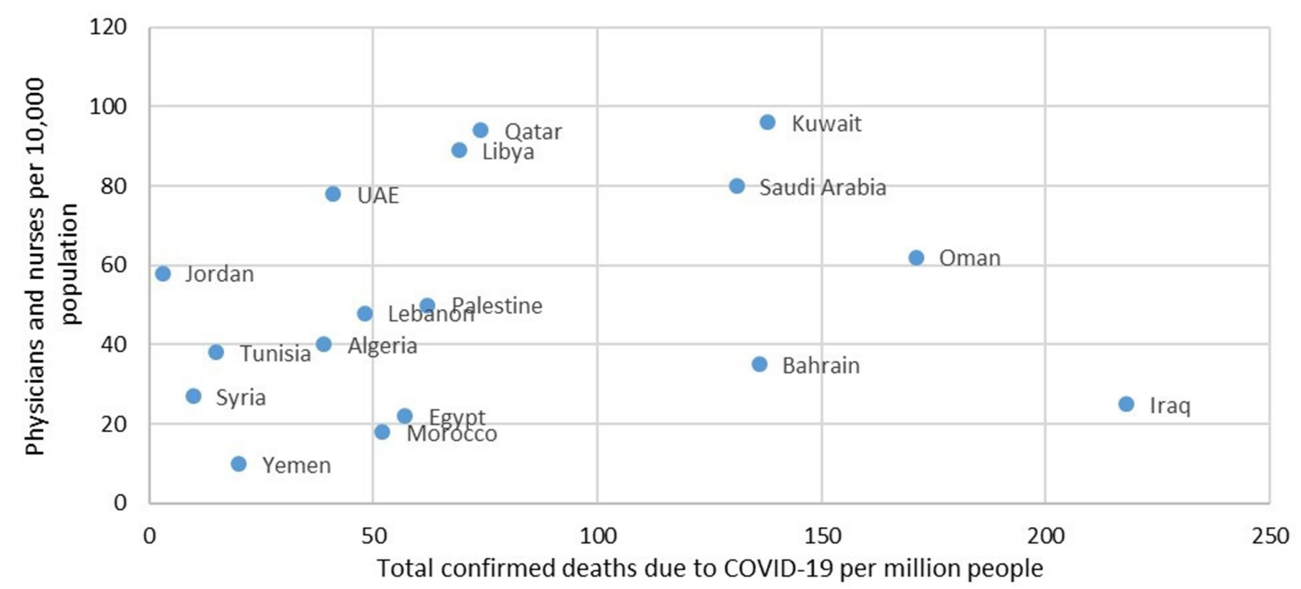

Figure II Health workforce in Arab countries (Source: WHO Report, 2018).

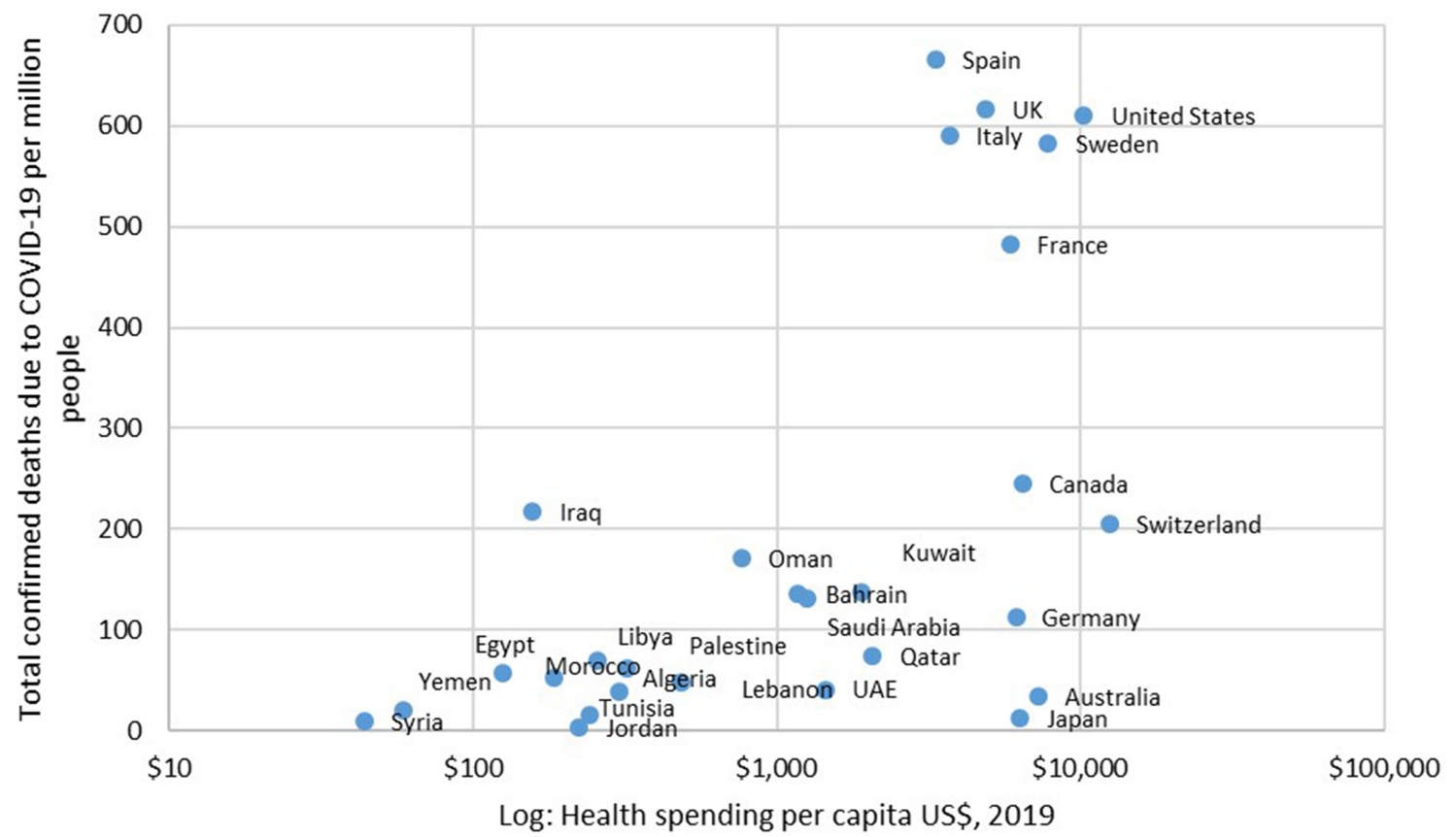

Figure 12 Health spending per capita in Arab countries vs COVID-19 deaths.

possible by testing frequently and tracing contacts only in the early stages. However, if the transmission is widespread, the containment by frequent testing is no longer possible. Therefore, more tests are more effective if the country focuses on containment measures that require blanket testing such as those done in the UAE and Bahrain. However, if the country focuses on containment, measures that do not require blanket testing such as Japan and Tunisia, more tests are not necessarily useful (Figure 1).

Health systems in Arab countries are different in enforcing health laws and social rules, and in managing, protecting, and testing high-risk individuals. Countries that focus on blanket testing, such as the UAE and Bahrain, resulted in a higher number of tests performed per confirmed case and they knew more about the true magnitude of the outbreak in the country. However, countries that focused on testing those at the highest risk only, such as Japan and Tunisia, resulted in a lower number of tests performed per confirmed case and they knew less about of the true size of the outbreak in the country (Figure 2). A study from two transplant centers in Saudi Arabia and Italy found that the awareness of nonpharmaceutical interventions is linked to the successful 
containment of COVID-19 in kidney transplant recipients as well as in the general population. ${ }^{25}$

In terms of the number of tests per confirmed death, a high number is preferable. Three groups of countries emerged: the UAE and Bahrain (group 1) had a high number of tests per death which indicated widespread testing and assessment of community transmission; Japan, Tunisia, Morocco, New Zealand, Australia, Qatar, Kuwait, Saudi Arabia, Canada, Switzerland and Iraq (group 2) had a low number of tests per death which indicated moderate testing and assessment of community transmission; the USA and the UK (group 3) had a low number of tests per death which indicated low testing and assessment of community transmission (Figure 3).

\section{Containment}

To assess the containment stage, four containment indicators we used namely; deaths per capita, deaths doubling time, cases per capita, and cases doubling time. If the doubling time is longer, the rate of transmission will be lower. In countries such as Australia, Egypt, and New Zealand, with few confirmed cases and a long doubling time are considered to have successfully contained the outbreak, although low testing capacity could still be a factor. On the other hand, few cases and a short doubling time such as in Jordan, Tunisia, Syria, Morocco, Libya and Lebanon suggest that the outbreak was spreading rapidly, and the number of cases is set to increase (Figure 4). Overall, Arab countries show less deaths per million and less doubling time for confirmed deaths compared to most OCED countries such as Italy, Spain, USA, UK, France and Canada. At first, it can seem surprising that the same virus can lead to such widely differing reported mortality rates between Arab countries and most OECD countries. The number of cases is less of a reliable measure than the number of deaths, because it is more likely to vary with testing capacity. Countries have different demographics and different COVID-19 death registration regulations, which make international comparison less informative. For example, the USA and the UK who have a high percentage of elderly population tend to have higher deaths due to COVID-19 per capita (Figure 5).

\section{Treatment}

To assess the treatment phase, one treatment indicator was used; case fatality rate. Countries with lower CFRs tend to have more of an effective response during the treatment phase. However, fatality rates vastly differ across countries, even if the populations are dying at the same rate. In order to differentiate between the two kinds of fatality rates, the case fatality rate (CFR) which is the proportion of people who die who have tested positive for the disease, and the Infection fatality rate (IFR) which is the proportion of people who die after having the infection. In countries such as the UAE, Bahrain, Australia, and New Zealand where testing is effective, the number of confirmed cases is a representation of the true number of infections. However, this was not the case in other countries, such as the Egypt, Algeria, Tunisia, Saudi Arabia, USA, the UK, and Italy. Countries, which have tested far more widely, are expected to have a lower case fatality rate. As a result, the case fatality rate is not comparable between countries (Figure 6).

The percentage of people above 60 years old in Italy $28 \%$, Germany $33 \%$, and Japan $28 \%$, respectively, compared to $7 \%$ in the Arab World. The global median age is about 30 years. Germany has the second highest median age at 47 years and Italy at 46 years, compared to 17 years in the Arab World. Given that the median age of confirmed COVID-19 cases is 51 years, older populations will have a higher case fatality rate (Figure 7). Besides the age factor, the presence of pre-existing diseases such as diabetes and cardiovascular diseases increases the chance of dying due to COVID-19. Arab Countries are not an exception; in fact, countries such as Egypt, Sudan, Syria, and Tunisia with a high prevalence of diabetes and cardiovascular disease have higher COVID-19 case fatality rates (Figure 8).

Another factor that is related indirectly to death from COVID-19 is the air pollution. The decrease in air pollution following the lockdown resulted in a decrease in the number of deaths due to air pollution, and a reduction in NCDs. ${ }^{26}$ However, a study highlights that more efforts should be made to completely avoid severe air pollution. ${ }^{27}$ The temporary reduction in air pollution due to lockdown activities is a good opportunity to inform policy and law makers on how to minimize air pollution on a long-term basis and save lives. ${ }^{28}$

Developing a vaccine against COVID-19 is a key strategy for reducing morbidity and mortality. Vaccine types include inactivated, live attenuated, vectored, nucleic acidbased, and recombinant subunit vaccines. ${ }^{29}$ Importantly, progressing from development of currently available vaccines to vaccinating at least $60 \%$ of eligible citizens and residents is the key to COVID-19 prevention. By 
December 2020 , countries ordered more than 10 billion vaccine doses. ${ }^{30}$ About 5 billion doses were ordered by high-income countries (14\% of the world's population). ${ }^{31}$ As of January 1st, 2021, only 4 Arab countries which include the UAE, Saudi Arabia, Bahrain, and Morocco began their COVID-19 vaccination campaigns (Figure 9).

In addressing COVID-19, different strategies have been applied: mitigation strategies focused on protecting the most vulnerable while flattening the peak (e.g. Sweden), suppression strategy to lower case numbers and outbreaks (e.g. UK, Jordan, Morocco), and elimination strategy to exclude disease and prevent community transmission (Australia, New Zealand, Bahrain, and UAE). In implementing such strategies, health laws established the institutional structures and processes through, and they set the limits for the exercise of coercive power over individuals and productions.

\section{Quality and Access}

In order to highlight the legal and health challenges faced during the pandemic, an analysis of the health systems resources in terms of quality and access, health workforce, and finance. The moderate Health and Quality (HAQ) Index performance of Arab countries may in fact contribute to the low number of deaths from COVID-19. OCED counterparts maintained higher levels of HAQ, however, they also have higher case of fatality rates, which indicates that other factors play a role such as demographics and availability of health workforce, and health finance (Figure 10).

Effective media and health communication constitute an important tool in COVID-19 control, not only to provide timely and accurate information to the public, but also to eliminate misinformation and disinformation. Trust in health systems is an important variable for effective implementation of COVID-19 health interventions. Preparedness planning is essential in order to respond effectively to outbreaks and epidemics, protecting populations at risk of severe disease, reducing the acute burden on healthcare services and reducing excess mortality. It is important to ensure the stability of health systems so that it delivers care efficiently and effectively through COVID-19 and beyond. Most Arab countries have limited access to ventilators for critical care, which is an important aspect of COVID-19 treatment, if not detected early enough. The concept of ventilators for critical care is almost limited in many Arab countries, which remains a drawback as COVID-19 not detected early and respiratory care remains an unchartered territory.

\section{Health Workforce}

COVID-19 puts the health workforce capacity under pressure and increased their risk of infection. ${ }^{32}$ COVID-19 led to premature deaths of doctors and nurses caring for COVID-19 patients, lack of personal protective equipment, and burnout amongst health workers. ${ }^{33}$ In the Arab countries, the ratio of doctors per 10,000 people is 14 on average. In Gulf Cooperation Council (GCC) countries, the trend shows that there is an increase in average number of doctors to 25 doctors per 10,000 people. This figure is low when compared to 35 doctors per 10,000 people in European Union (EU). Nursing personnel in Arab countries have also increased significantly to an average of around 47 per 10,000 population. Furthermore, over 15,000 new hospital beds have been recently added, reaching around 20 per 10,000 people, compared to 52 in EU. ${ }^{34}$

Protecting health workers who risk their lives to fight the pandemic is one of the biggest priorities in Arab Countries. There is a need to prioritize commitment towards COVID-19 and invest substantially towards having a better health infrastructure and capacity building through investment in the health workforce. Having adequate numbers of health workers will be vital to counter COVID-19. Access to personal protective equipment, protocols of occupational health and safety, and adequate rest and recovery periods, will determine how effectively health workers can treat patients. Regulatory and policy changes aimed at expanding workforce capacity and supporting telehealth in service delivery were put in place by many Arab Countries. Such policy changes include expanding the scope of practice for some health professions, relaxing health professional licensing rules, and supporting the provision of telehealth services. ${ }^{35}$

Goal 3 of the Sustainable Development Goals aims to ensure that all have access to health and health coverage. ${ }^{18}$ In many Arab Countries, meeting this goal is hindered by the underutilization of the skills of physicians, nurses and pharmacists, and by low ratios of nurses and other personnel to physicians, and of generalists to specialists. In many countries, the capacity to restore regular health services, while at the same time continuing to address COVID-19 is limited. ${ }^{36}$ In order to maximize the current health workforce, strategies such as licensing flexibility, maximizing scope of practice, telehealth, and redeploying health workers to high-need areas were implemented. ${ }^{37}$ 


\section{Finance and Taxes}

Arab countries constitute $6 \%$ of the world's population yet they only spend $2 \%$ of global spending on the healthcare sector. Arab countries spent $6 \%$ of their GDP on health in 2017, almost half that observed globally. About $43 \%$ of the money was spent to support COVID-19 activities were in fact spent on financial support policies, $32 \%$ on multiple policy categories, and $16 \%$ on general policy support. Development assistance for low- and middle-income countries remains a fraction of what is needed to fully address the effects of the pandemic. Continued efforts are needed to raise the required resources to mitigate the pandemic for the most vulnerable and to help curtail the pandemic for all.

Most Arab countries have announced they will cover all medical costs associated with dealing with COVID-19 for their citizens in the governmental sector. Employees infected with COVID-19 were given paid leave. However, many patients were forced to pay high cost in the private sector. This formed a sense of financial uncertainty and an environment where COVID-19 patients may want to not disclose that they are infected. Universal coverage usually is attained in countries in which public financing of health is around $5 \%$ of GDP. ${ }^{38}$ Continued efforts are needed to raise the required resources to mitigate the pandemic for the most vulnerable. In many Arab countries, additional revenues can be raised without imposing additional taxes, by implementing a fair progressive taxing system, supported by strong institutional capacity. Principles of social solidarity are crucial to combat COVID-19. Health systems with universal coverage based either on social insurance or general taxation are more effective than health systems without universal coverage. Providing skill-mix staff and task shifting are vital tools to deliver preventive care and effective COVID-19 treatment.

Public health activities such as research and surveillance were more emphasized due to COVID-19. COVID-19 vaccine is the best way to eradicate COVID-19. Without an effective vaccine, prevention of transmission remains the only weapon. Implementing measures to reduce the risk of transmission such as wearing masks in public, social distancing, wash hands, and avoiding crowds is vital. Telemedicine will finally become a part and a parcel of daily medical consultations mainstream and Arab countries need to consider alternative models of care to move services from hospitals to home-based care. More investment in public health preparedness and surveillance, and more investment in research, vaccines, therapeutics, and non-medical methods of prevention are needed. Health providers need to consider the lessons learnt and new consumer habits to adopt telehealth and to plan for a health system with a strong infrastructure for future generations.

\section{Conclusion}

This study has identified important lessons to be learnt on how Arab Countries have responded to COVID-19. Legal intervention has been a visible response to the COVID-19 pandemic in Arab Countries. A legal and health response includes a combination of conventional disease control measures (testing, contact-tracing, and social distancing), population-based physical distancing (including stay-at-home orders, school and business closures, and social gathering bans), travel limits (including travel bans, and border closures), and economic support measures. There are a number of challenges faced by Arab health systems which have are amplified due to COVID-19 and if ignored or overlooked they will present considerable challenges in the near future. Health systems in Arab countries are not sufficiently equipped to handle deal with the various healthcare needs related to COVID-19, in particular issues pertaining to administration, finances, supply side of healthcare, and the effective utilization of information technology in order to make informed data-driven decisions. Acceptable healthcare quality and access, a competent health workforce, and sufficient funds are imperative needs in the healthcare system in order to provide sustainable response to COVID-19. Health systems in Arab Countries need to enhance emergency preparedness by developing, training and equipping an effective workforce for health emergency, maintaining structurally and functionally safe hospitals and other health facilities, supplying high-quality COVID-19 medicines and vaccine, providing disease surveillance systems and decentralized laboratory services, delivering sound health service to people directly affected by the COVID-19 crisis and other serious health conditions, in addition to health financing and taxes.

\section{Abbreviations}

COVID-19, novel coronavirus disease; SARS-CoV-2, severe acute respiratory syndrome coronavirus 2; WHO, World Health Organization; HAQ Index, Healthcare Access and Quality Index; HDI, Human Development Index; OECD, Organization for Economic Co-operation and Development; CFR, case fatality rate; IFR, Infection fatality rate; NCDs, Non-Communicable Diseases; ESCWA, Economic and Social Commission for Western Asia; UAE, United Arab 
Emirates; UK, United Kingdom; USA, United States of America; EU, European Union; GCC, Gulf Cooperation Council.

\section{Disclosure}

The authors report no conflicts of interest for this work.

\section{References}

1. World Health Organization. Modes of transmission of virus causing COVID-19: implications for IPC precaution recommendations. 2020c. Available from: Scientificbrief.WHOreferencenumber:WHO/ 2019-nCoV/Sci_Brief/Transmission_modes/2020.2https://www.who. $\mathrm{int} /$ news-room/commentaries/detail/modes-of-transmission-of-viruscausing-COVID-19-implications-for-ipc-precaution-recommenda tions. Accessed March 3, 2021.

2. Ritchie RM, Ortiz-Ospina H, Hasell E. Coronavirus Pandemic (COVID-19). 2020. OurWorldInData.org. Available from: https://our worldindata.org/coronavirus. Accessed March 8, 2021.

3. World Health Organization. Coronavirus Disease 2019 (COVID-19) Situation Report - 46. 2020b.

4. Wang C, Horby PW, Hayden FG, Gao GF. A novel coronavirus outbreak of global health concern. Lancet. 2020;395(10223): 470-473. doi:10.1016/S0140-6736(20)30185-9

5. Bherwani H, Anjum S, Kumar S, et al. Understanding COVID-19 transmission through bayesian probabilistic modeling and GIS-based voronoi approach: a policy perspective. Environ Dev Sustainability. 2020:1-19. doi:10.1007/s10668-020-00849-0

6. Arab Center Washington DC. The Coronavirus Pandemic and the Arab World: Impact, Politics, and Mitigation. 2020.

7. United Nations. Policy brief: the impact of COVID-19 on the Arab region an opportunity to build back better. 2020. Available from: https://www.unescwa.org/sites/www.unescwa.org/files/sg_policy_ brief_COVID-19_and_arab_states_english_version_july_2020.pdf. Accessed March 8, 2021.

8. UNDP. Arab human development report. Enabling youth to shape their own future key to progress on development and stability in Arab region. 2016. Available from: https://www.refworld.org/docid/ 58407d774.html. Accessed November 17, 2020.

9. The World Bank. World development indicators. 2020. Available from: https://data.worldbank.org/indicator/NY.GDP.PETR.RT.ZS. Accessed September 20, 2020.

10. Fullman N, Yearwood J, Abay SM, et al. Measuring performance on the healthcare access and quality index for 195 countries and territories and selected subnational locations: a systematic analysis from the Global Burden of Disease Study 2016. Lancet. 2018;391 (10136):2236-2271. doi:10.1016/S0140-6736(18)30994-2

11. World Health Organization. Everybody Business: Strengthening Health Systems to Improve Health Outcomes: WHO's Framework for Action. 2007. ISBN 9789241596077.

12. World Health Organization. A Strategic Framework for Emergency Preparedness. Geneva: World Health Organization; 2016. Licence: CC BY-NC-SA 3.0 IGO. Available from: https://apps.who.int/iris/ bitstream/handle/10665/254883/9789241511827-eng.pdf;jsessionid= 4744842F6D4E949F2D3F64F7B31D94CC? sequence=1. Accessed March 8, 2021.

13. Global Burden of Disease Study (GBD). Available from: http://www. healthdata.org/gbd/2019. Accessed September 24, 2020.

14. ESCWA. The impact of COVID-19 on older persons in the Arab Region. 2020. E/ESCWA/2020/Policy Brief.12. Available from: https://www.unescwa.org/sites/www.unescwa.org/files/uploads/ impact-COVID-19-older-persons-arab-region-english.pdf. Accessed March 8, 2021.
15. The Epidemiological Characteristics of an Outbreak of 2019 Novel Coronavirus Diseases (COVID-19), China. The novel coronavirus pneumonia emergency response epidemiology team. China CDC Wkly. 2020. Available from: https://cdn.onb.it/2020/03/COVID-19. pdf.pdf. Accessed March 8, 2021.

16. World Health Organization, EMRO Office. NCDs and COVID-19 in the Eastern Mediterranean Region. 2021. Available from: http://www. emro.who.int/noncommunicable-diseases/publications/ncds-and-covid -19-in-the-eastern-mediterranean-region.html. Accessed February 7, 2021.

17. The Novel Coronavirus Pneumonia Emergency Response Epidemiology Team. Vital surveillances: the epidemiological characteristics of an outbreak of 2019 novel coronavirus diseases (COVID-19) in China, 2020. China CDC Wkly. 2020. doi:10.46234/ ccdcw2020.097

18. Gupta A, Bherwani H, Gautam S, et al. Air pollution aggravating COVID-19 lethality? Exploration in Asian cities using statistical models. Environ Dev Sustainability. 2020. doi:10.1007/s10668-02000878-9

19. Gautam S. The influence of COVID-19 on air quality in India: a boon or inutile. Bull Environ Contam Toxicol. 2020;104(6):724-726. doi:10.1007/s00128-020-02877-y

20. Muhammad S, Long X, Salman M. Covid-19 pandemic and environmental pollution: a blessing in disguise? Sci Total Environ. 2020;728:138820. doi:10.1016/j.scitotenv.2020.138820

21. Bherwani H, Nair M, Musugu K, et al. Valuation of air pollution externalities: comparative assessment of economic damage and emission reduction under COVID-19 lockdown. Air Quality, Atmosphere \& Health. 2020;13(6):683-694. doi:10.1007/s11869020-00845-3

22. World Health Organization. Working for health and growth: investing in the health workforce - report of the high-level commission on health employment and economic growth. 2016. Available from: http://apps.who.int/iris/bitstream/10665/250047/1/9789241511308eng.pdf. Accessed March 8, 2021.

23. World Health Organization. Report on Primary Health Care in the Eastern Mediterranean Region: Review of Progress Over the Last Decade (2008-2018). Cairo: World Health Organization Regional Office for the Eastern Mediterranean; 2018.

24. Economic and Social Commission for Western Asia (ESCWA). Regional emergency response to mitigate the impact of COVID-19. 20-00116 - E/ESCWA/2020/INF.3. 2020. Available from: https:// www.unescwa.org/sites/www.unescwa.org/files/publications/files/2000116_rer_mitigatingimpact_COVID-19_eng_april8.pdf. Accessed March 8, 2021.

25. Monaco A, Manzia TM, Angelico R, et al. Awareness and impact of non-pharmaceutical interventions during coronavirus disease 2019 pandemic in renal transplant recipients. Transplant Proc. 2020;52 (9):2607-2613. doi:10.1016/j.transproceed.2020.07.010

26. Dutheil F, Baker JS, Navel V. COVID-19 as a factor influencing air pollution? Environ Pollut. 2020;263(Pt A):114466. doi:10.1016/j. envpol.2020.114466

27. Wang P, Chen K, Zhu S, Wang P, Zhang H. Severe air pollution events not avoided by reduced anthropogenic activities during COVID-19 outbreak. Resour Conserv Recycl. 2020;158:104814. doi:10.1016/j.resconrec.2020.104814

28. Gautam S. COVID-19: air pollution remains low as people stay at home. Air Qual Atmos Health. 2020;13(7):853-857. doi:10.1007/ s11869-020-00842-6

29. Gao S, Song SQ, Zhang LL. Recent progress in vaccine development against chikungunya virus. Front Microbiol. 2019;10:2881. doi:10. 3389/fmicb.2019.02881

30. Mullard A. How COVID vaccines are being divvied up around the world Canada leads the pack in terms of doses secured per capita. Nature. 2020. doi:10.1038/d41586-020-03370-6. 
31. So AD, Woo J. Reserving coronavirus disease 2019 vaccines for global access: cross sectional analysis. BMJ. 2020;371:m4750. doi:10.1136/bmj.m4750.

32. Adams JG, Walls RM. Supporting the health care workforce during the COVID-19 global epidemic. JAMA. 2020;323(15):1439-1440. doi:10.1001/jama.2020.3972

33. Azzopardi-Muscat N. A public health approach to health workforce policy development in Europe. Eur J Public Health. 2020;30 (Supplement_4):iv3-iv4. doi:10.1093/eurpub/ckaa123

34. Global Health Security Index. 2020. Available from: https://www. ghsindex.org.https://www.unescwa.org/publications/socioeconomicimpact-COVID-19-policy-briefs. Accessed March 8, 2021.

35. Aith F, Castilla Martínez M, Cho M, et al. Is COVID-19 a turning point for the health workforce? Rev Panam Salud Publica. 2020;44: e102. doi:10.26633/RPSP.2020.102
36. WHO Regional Office for Europe. Strengthening and adjusting public health measures throughout the COVID-19 transition phases. Policy considerations for the WHO European region. April 24, 2020. Available from: https://www.euro.who.int/en/ health-topics/health-emergencies/coronavirus-COVID-19/techni cal-guidance/2020/strengthening-and-adjusting-public-healthmeasures-throughout-the-COVID-19-transition-phases.-policyconsiderations-for-the-who-european-region,-24-april-2020. Accessed June 14, 2020.

37. Chen C, Pittman P, Westergaard S, Salsberg E, Erikson C. Emerging health workforce strategies to address COVID-19. Health Aff Blog. 2020.

38. World Health Organization. Health Financing Strategy for the Asia Pacific Region (2010-2015). Geneva: World Health Organization; 2009.
Risk Management and Healthcare Policy

\section{Publish your work in this journal}

Risk Management and Healthcare Policy is an international, peerreviewed, open access journal focusing on all aspects of public health, policy, and preventative measures to promote good health and improve morbidity and mortality in the population. The journal welcomes submitted papers covering original research, basic science, clinical \& epidemiological studies, reviews and evaluations,

\section{Dovepress}

guidelines, expert opinion and commentary, case reports and extended reports. The manuscript management system is completely online and includes a very quick and fair peer-review system, which is all easy to use. Visit http://www.dovepress.com/testimonials.php to read real quotes from published authors. 